\title{
Diversity of Pepper (Capsicum spp.) Genotypes from Eritrea Assessed by Morphological Traits
}

\author{
Brhan Khiar Saleh ${ }^{1,2}$, Remmy W. Kasili ${ }^{2}$, Edward G. Mamati ${ }^{2}$, Woldeamlak Araia ${ }^{1}$ \& Aggrey B. Nyende ${ }^{2}$ \\ ${ }^{1}$ Hamelmalo Agricultural College, Keren, Eritrea \\ ${ }^{2}$ Jomo Kenyatta University of Agriculture and Technology, Nairobi, Kenya \\ Correspondence: Brhan Khiar Saleh, Hamelmalo Agricultural College, P.O. Box 397, Keren, Eritrea. Tel: \\ 254-708-963-891; 291-711-7725. E-mail: brhan200220@yahoo.co.uk
}

Received: January 26, 2016 Accepted: March 9, 2016 Online Published: March 15, 2016

doi:10.5539/jas.v8n4p156 URL: http://dx.doi.org/10.5539/jas.v8n4p156

\begin{abstract}
Diversity in plant genetic resources provides an opportunity for plant breeders to develop new and improved cultivars with desirable characteristics. The purpose of this study was to assess the diversity of Eritrean pepper germplasm in order to obtain information for improving it. A total of 60 pepper (Capsicum spp.) seed sample collections were obtained from farmers and institutions in Eritrea. The collections were evaluated at two sites located in two different agro-climatic regions of the country. The collections were assessed using 16 quantitative and 23 qualitative descriptors. A Randomized Complete Block Design was used for the evaluation. Quantitative and qualitative data of the two sites were subjected to Principal Component Analysis, Principal Coordinate Analysis, Hierarchal clustering, Analysis of variance and Correlation. The distribution of characters of the different quantitative and qualitative traits and the performance of the collections showed the existece of variable characters distributed among the collections indicating considerable diversity. For quantitative variables, the first three components were able to explain $61 \%, 58 \%$ and $67 \%$ of the total variation in Hamelmalo, Asmara and combined data of the two sites respectively. While for the qualitative variables the first three components were able to explain a variation of $58 \%$ in Hamelmalo, $49 \%$, in Asmara and $55 \%$ combined data of the two sites. Phenological attributes and fruit characteristics were found to contribute more to the variation. The majority of the traits evaluated were significant and the highest Coefficient of Variation was related to fruit characteristics. The results of this study showed that there is sufficient variability within the Eritrean pepper genotypes that could be used in future breeding and crop improvement programs.
\end{abstract}

Keywords: diversity, Eritrea, Capsicum spp., morphological traits, principal components, farmer varieties

\section{Introduction}

Plant genetic diversity is the heritable variation among plant species (Rao \& Hodgkin, 2002). Diversity in plant genetic resources provides an opportunity for plant breeders to develop new and improved cultivars with desirable characteristics, which include both farmer- and breeders preferred traits (Govindaraj et al., 2015). Understanding the genetic relationships between chilli accessions may provide an effective management tool for their conservation, as well as to help in a plant breeding program (Votava et al., 2005). Variation in local germplasm has long been utilized for identifying the potential for breeding to meet desirable traits. The findings of Adetula and Olakojo (2006) in Nigeria, Balkaya and Karaagc (2009) and Bozakalfa et al. (2009) in Turkey and Naujeer (2009) in Mauritius working in eggplant, are proper examples of identifying variability within the locally available germplasm that can be utilized for future breeding and crop improvement program.

In Eritrea the National Agricultural Research Institute has been running a selection program from local germplasm for several years that has resulted in the identification of five superior breeding lines (NARI, 2013). However, there have not been any previous studies on genetic diversity of Eritrean pepper. Genetic diversity studies are the first basic step in a meaningful breeding programme and therefore require accurate and reliable means for estimation (Aremu, 2012). Presence of genetic variability in crops is essential for its further improvement by providing options for the breeders to develop new varieties and hybrids (Govindaraj et al., 2015). In Eritrea, farmers usually save their own seed and transfer it from one generation to the next. However, proper seed production methods including isolation techniques are not in practice within and among farms, giving chance to out-cross and introgression forces to take place. In addition seed exchange across the border 
with Ethiopia has been active for a long period of time since the colonial period whereby numerous exotic varieties have been introduced. This is the reason as to why local pepper sold in the market is of mixed pods containing wide range of fruit size, color, pungency etc. reflecting the rich genetic variation existing in the local genotypes. Thus, the aim of the current study was to evaluate local pepper genotypes for diversity using morphological characteristics, and make the necessary information available for future breeding and crop improvement programs in Eritrea.

\section{Materials and Methods}

\subsection{Plant Materials}

A total of 60 seed sample collections (Table 1) collected from farmers and institutions were used in this study. These are 52 from farmers, six breeding lines from Hamelmalo Agricultural College and two breeding lines from the Nationa Agriculural Research Institute. The 52 samples collected from farmers have not been given varietal names but are a kind of heirlooms saved by farmers and transferred from one generation to the next and exchanged among farmers within the village or beyond. Thus they are denoted here as farmer varieties or collections.

Table 1. Genotypes used in the study and their collection area, by sub-region, region and agro-climatic zone

\begin{tabular}{llll}
\hline Collections & Sub-region & Region/Institute & Agroclimatic zone \\
\hline ANE01, ANE03, ANE04, ANE07, ANE08 & Elabered & Anseba & WEZ \\
$\begin{array}{l}\text { DDK02, DDK03, DDK05 } \\
\text { DME01, DME04, DME05, DME06, DME09, DME10, DME12 }\end{array}$ & $\begin{array}{l}\text { Dekemhare } \\
\text { Mendefera }\end{array}$ & $\begin{array}{l}\text { Debub } \\
\text { Debub }\end{array}$ & SCHZ \\
$\begin{array}{l}\text { DDB02, DDB03, DDB04, DDB06 } \\
\text { NRSG01, NRSG02, NRSG03, NRSG04, NRSG05, NRSG06, }\end{array}$ & Gindae & Nebub & \\
NRSG09, NRSG27 & & & CPZ \\
NRSG12, NRSG14, NRSG15,NRSG17, NRSG18, NRSG19, & Gindae & NRS & GB \\
NRSG21, NRSG22, NRSG24 & & & \\
$\begin{array}{l}\text { NRSF01, NRSF02, NRSF04 } \\
\text { NRSAF01, NRSAF02, NRSAF04, NRSAF06, NRSAF07, }\end{array}$ & Afabet & NRS & CPZ \\
$\begin{array}{l}\text { NRSAF08, NRSAF09, NRSAF10, NRSAF11, NRSAF12, } \\
\text { NRSAF14, NRSAF18, NRSAF19, NRSAF20 }\end{array}$ & & & NCHZ \\
$\begin{array}{l}\text { Red-long, Red-short } \\
\text { HD0031, HD0083, HD0108, HD0123, HD0128, HD0134 }\end{array}$ & Hamelmalo & Anseba & WEZ \\
\hline
\end{tabular}

\subsection{Study Locations}

The testing locations were Hamelmalo Agricultural College located at $15^{\circ} 52^{\prime} 35^{\prime \prime} \mathrm{N}$ and $38^{\circ} 27^{\prime} 45^{\prime \prime} \mathrm{E}$ with an elevation of $1264 \mathrm{~m}$ above sea level and Asmara (Halibet) located at $15^{\circ} 18^{\prime} 42^{\prime \prime} \mathrm{N}$ and $38^{\circ} 56^{\prime} 15^{\prime \prime} \mathrm{E}$ with an elevation of $2335 \mathrm{~m}$ above sea level. Average annual rainfall and temperature in Asmara for the period 2008-2013 was $408 \mathrm{~mm}$ and $8.8{ }^{\circ} \mathrm{C}$ respectively, while for Hamelmalo the average for the period 2010-2012 it was $415 \mathrm{~mm}$ and $21.7^{\circ} \mathrm{C}$.

\subsection{Experimental Design and Data Collection}

The seeds were sown in nursery beds and transplanted into $1 \mathrm{~m}$ wide and $3.4 \mathrm{~m}$ long beds with inter and intra raw spacing of $50 \mathrm{~cm}$. Each plot accommodated 12 plants. A Randomized Complete Block Design (RCBD) with three replications was used in each site. A total of of 39 quantitative and qualitative (IPGRI et al., 1995) morphological characters were recorded. These were seedling, phenology, leaf, flower and fruit characteristics. Data was collected from four randomly selected plants from the centre of the bed.

\subsection{Data Analysis}

The data was analysed using GENSTAT Discovery edition 4, version 10.3.0.0 (VSN International Ltd., 2011) software and the data was subject to Analysis of variance, Principal component analysis (PCA) and Principal coordinate analysis (PCoA). The PCA was run using the 16 quantitative and 23 qualitative data sets. A scree diagram was used to identify the number of components to be used for analysis. After that, Principal component analysis was run using six components for the quantitative data and 5 for the qualitative. A Varimax rotation was used in order to get clear structure of the components. The variants that scored lower than 0.4 were excluded for 
improving the percentage explained by the six components. Consequently all the 16 quantitative traits were found to explain enough variation in the data. While for qualitative characters only 10 characteristics scored 0.4 or higher were selected. Based on results of the principal component analysis the 13 quantitative and 10 qualitative characteristics were used for hierarchical cluster analysis of the genotypes.

\section{Results}

\subsection{Morphological Description and Performance}

Based on average value of the two sites, the germplasm was separated into different character groups of each qualitative trait. The distribution of the characteristics within the traits for the 23 qualitative traits showed a wide range of variation for most of the traits (Table 2). Only five traits showed no variation. These were leaf margin, leaf pubescence, calyx margin, corolla colour and blossom end appendage. The predominant characters $(100 \%$ occurrence) were entire leaf margin, sparse leaf pubescence, dentate calyx margin, white corolla color and absence of fruit blossom end appendage. Other traits showed low variation such as cotyledon leaf shape of which $90.5 \%$ of the collections were lanceolate. Some traits showed a mixture of values thus described as mixed. In most traits the distribution of the characters was even. However, for some of the traits the values were skewed towards certain characters, for instance lanceolate cotyledon leaf shape $(91 \%)$, elongate fruit shape $(73.7 \%)$ and sparse stem pubescence $(75.8 \%)$, while characters showed low values are white hypoctyle color $(3.2 \%)$ and sunken fruit shape at blossom end (1.1\%) (Table 2).

The coefficient of variation (CV\%) of all traits except PGH was greater than $20 \%$. Fruit traits showed higher CV percentages compared to plant, leaf and seedling traits. The highest CV\% was recorded by NBF (180) followed by CAC (87) (Table 2).

Table 2. Percentage distribution of characters for 14 qualitative traits that showed variation

\begin{tabular}{lllll}
\hline Trait & Occurrence of traits (\%) & & & CV\% \\
\hline HC & Purple=64.2 & Green=32.6 & White=3.2 & 23.1 \\
HP & Sparse=43.2 & Intermediate=50.5 & Dense=7.4 & 29.7 \\
PGH & Intermediate=36.8 & Erect=63.2 & & 14.2 \\
SP & Sparse=75.8 & Intermediate=24.2 & & 22.2 \\
LSh & Ovate=50.5 & Lanceolate=29.5 & Mixed=17.9 & 23.5 \\
CAC & Present=45.3 & Absent=43.2 & Mixed=11.6 & 87.8 \\
FCMS & Light red=57.9 & Dark red=23.2 & Light brown=7.4 & Brown=9.5 \\
FSh & Elongate=73.7 & Triangle=15.8 & Mixed=10.5 & 41.9 \\
FP & Erect=34.7 & Intermediate=53.7 & Mixed=11.6 & 53.6 \\
FShBE & Blunt=61.1 & Pointed=37.9 & Sunken=1.1 & 16.4 \\
FShPA & Truncate=47.4 & Obtuse=34.7 & Cordate=6.3 & 42.7 \\
FS & Smooth=42.1 & Semi-Wrinkled=50.5 & Mixed=7.4 & Mixed=11.6 \\
NBF & Absent=54.7 & Mixed=45.3 & & 28.7 \\
FCSC & Semi-Corrugated=50.5 & Intermediate=34.7 & Mixed=14.7 & 29.6
\end{tabular}

Note. $\mathrm{HC}=$ Cotyledon color; $\mathrm{HP}=$ Cotyledon pubescence; $\mathrm{CLSh}=$ Cotyledon leaf shape $\mathrm{CAC}=$ Calyx annular constriction; FCMS $=$ Fruit color at mature stage; FCSC $=$ Fruit cross sectional corrugation; FP = Flower position; FShBE $=$ Fruit shape at blossom end; FShPA = Fruit shape at pedicel attachment; FS = Fruit surface; $\mathrm{LSh}=$ Leaf shape; $\mathrm{SP}=$ Stem pubescence; $\mathrm{PGH}=$ Plant growth habit.

The collections also showed variable characteristics in the different quantitative traits (Table 3). Plant height (PHt) categories were short $(34-43.99 \mathrm{~cm})$, medium $(44-53.99 \mathrm{~cm})$ and tall $(54-68 \mathrm{~cm})$. The majority of the collections (78.3\%) were in the medium category and only $5 \%$ were tall. Collections were classified into those with thick stem $(15-19 \mathrm{~mm})$, medium $(12-14.99 \mathrm{~mm})$ and thin $(7-11.99 \mathrm{~mm})$. Only $5 \%$ of the collections were with stem thickness in the range 7-11.99 $\mathrm{mm}$, while the majority were in the medium stem thickness category. Mature leaf length ranged from short $(5-7.99 \mathrm{~cm})$ to long $(\geq 11 \mathrm{~cm})$, however, the majority $(76.7 \%)$ of the collections were in the medium category which ranged $8-10.99 \mathrm{~cm}$. Only $3.3 \%$ of the collections had wide life $(\geq$ $5.5 \mathrm{~cm}$ ), while the majority $(75 \%)$ were in the medium category $(4-5.49 \mathrm{~cm}$ ) and $21.7 \%$ were $2.5-3.99 \mathrm{~cm}$ (Table $3)$. 
Phenological traits were categorized as early, medium and late. The majority of the collections $(72.6 \%)$ were medium in days to germination (11-13 days), while both early (8-10 day) and late (14-16 days) germinating collections were each $13.7 \%$. The earliest to flower collections (20\%) were in the range $42-49.99$ days and the late collections (15\%) flowered 55-60 days, while the rest were medium. The majority of the collections (88.3\%) of the collections were medium in days to fruiting (60-69.99) and 8.3\% were early fruiting (50-59.99 days), while late flowering (70-80 days) were only 3.3\% (Table 3 ).

Variable quantitative fruit characteristics were recorded (Table 3). Short fruit length $(7-8.99 \mathrm{~cm})$ represented $15 \%$ of the collections while long fruits $(11-13 \mathrm{~cm})$ were only $8.3 \%$, while the majority $(76.7 \%)$ were medium in fruit length. Variation in fruit width was more balanced where $18 \%$ of the collections were with wide fruits (3-4 $\mathrm{cm})$ and the slim fruits $(1-1.99 \mathrm{~cm})$ were $35 \%$ of the collection. The rest $(47 \%)$ were medium in fruit width (22.99). In reverse to that $58.3 \%$ of the collections had thin fruit wall thickness (1-1.99 mm), $40 \%$ medium (2-2.99 $\mathrm{mm}$ ) and only $1.7 \%$ had thich wall thichness $(3-4 \mathrm{~mm})$. Fruit weight showed high variation. Collections with small fruits (4.5-14.99 g) were 53\%, medium (15-24.99 g) 27\% and large fruits ( $\geq 25 \mathrm{~g}$ ) 20\% (Table 3). Both number of fruits and yield per plant showed balanced distribution among the categories. Collections with a low number of fruits (19-38.99) and low yield (140-339.99 g) were $25 \%$ and $23.3 \%$, respectively, while a medium number of fruits (39-58.99) and the yield (340-539.99) were $45 \%$ and $48.3 \%$, respectively, and collections with large number of fruits $(\geq 59)$ and high yield $(\geq 540 \mathrm{~g}$ ) were $30 \%$ and $28.3 \%$ of the collections respectively (Table $3)$.

\subsection{Variability of Quantitative Traits}

The analysis of variance of the quantitative traits (Table 4) showed that at Hamelmalo the differences among the 95 collections were significant for all traits except for DFl, DFr, PHt and TSS. In Asmara the differences were significant for all traits except for FL and Y/Pl. The analysis of the data when combined from the two sites showed that the major source of variation was due to genotype followed by location while genotype $\mathrm{x}$ location interaction was not significant. Genotype was significant for all traits except for TSS, while location was significant for all traits except for FL, FW and FWt it was not significant. The genotype $\mathrm{x}$ location interaction was only significant for FWt, Y/Pl, TSS and DFl (Table 4).

Table 3. Percentage distribution of pepper collections grouped into three categories for 13 quantitative traits based on combined data of the two locations

\begin{tabular}{|c|c|c|c|c|c|c|c|}
\hline $\mathrm{Pht}(\mathrm{cm})$ & $\%$ & $\mathrm{STh}(\mathrm{mm})$ & $\%$ & $\operatorname{MLL}(\mathrm{cm})$ & $\%$ & MLW $(\mathrm{cm})$ & $\%$ \\
\hline $34-43.99$ & 16.7 & $7-11.99$ & 5 & $5-7.99$ & 8.3 & $2.5-3.99$ & 21.7 \\
\hline $44-53.99$ & 78.3 & $12-14.99$ & 68.3 & 8-10.99 & 76.7 & $4-5.49$ & 75 \\
\hline $54-68.00$ & 5 & $15-19.00$ & 26.7 & $\geq 11$ & 15 & $\geq 5.5$ & 3.3 \\
\hline $\mathrm{DG}$ & $\%$ & DFl & $\%$ & $\mathrm{DFr}$ & $\%$ & FL (cm) & $\%$ \\
\hline $8-10$ & 13.7 & $42-49.99$ & 20 & $50-59.99$ & 8.3 & $7-8.99$ & 15 \\
\hline $11-13$ & 72.6 & $50-54.99$ & 65 & $60-69.99$ & 88.3 & $9-10.99$ & 76.7 \\
\hline $14-16$ & 13.7 & $55-60$ & 15 & $70-80.00$ & 3.3 & $11-13.00$ & 8.3 \\
\hline $\mathrm{FW}(\mathrm{cm})$ & & FWTh $(\mathrm{mm})$ & & FWt $(\mathrm{g})$ & & $\mathrm{NFr} / \mathrm{P}$ & \\
\hline $1-1.99$ & 35 & $1-1.99$ & 58.3 & $4.5-14.99$ & 53 & $19-38.99$ & 25 \\
\hline $2-2.99$ & 47 & $2-2.99$ & 40 & $15-24.99$ & 27 & $39-58.99$ & 45 \\
\hline $3-4.00$ & 18 & $3-4.00$ & 1.7 & $\geq 25$ & 20 & $\geq 59$ & 30 \\
\hline \multicolumn{8}{|l|}{$\mathrm{Y} / \mathrm{P}(\mathrm{g})$} \\
\hline $140-339.99$ & 23.3 & & & & & & \\
\hline $340-539.99$ & 48.3 & & & & & & \\
\hline$\geq 540$ & 28.3 & & & & & & \\
\hline
\end{tabular}

Note. PHt $=$ Plant height; $\mathrm{STh}=$ Stem thickness $; \mathrm{LML}=$ Mature leaf length; $\mathrm{LMW}=$ Mature leaf length; $\mathrm{DG}=$ Days to Germination; DFl = Days to flowering; $\mathrm{DFr}=$ Days to fruiting; $\mathrm{FL}=$ Fruit length $(\mathrm{cm}) ; \mathrm{FW}=$ Fruit width $(\mathrm{cm}) ; \mathrm{FWTh}=$ Fruit wall thickness $(\mathrm{mm}) ; \mathrm{FWt}=$ Fruit weight $(\mathrm{g}) ; \mathrm{NFr} / \mathrm{P}=$ No of fruits per plant; $\mathrm{Y} / \mathrm{Pl}=$ Yield per plant. 
High coefficient of variation was recorded on NFr/P, FWt and Y/Pl. At Hamelmalo it was 42.3\%, 39.4\% and $37.3 \%$ respectively and in Asmara it was 31.3\%, 37.4\% and 35\% respectively. When data of the two sites was combined it was $43.5 \%, 39.9 \%$ and $41.7 \%$ respectively (Table 4 ).

Table 4. Mean values from analysis of variance of quantitative tarits recorded on pepper genotypes grown at two locations

\begin{tabular}{|c|c|c|c|c|c|c|c|c|c|c|c|c|}
\hline \multirow{3}{*}{ Trait } & \multicolumn{3}{|c|}{ Hamelmalo } & \multicolumn{3}{|c|}{ Asmara } & \multicolumn{6}{|c|}{ Combined of the two sites } \\
\hline & \multirow{2}{*}{ Mean } & \multirow{2}{*}{ StDv } & \multirow{2}{*}{ CV $(\%)$} & \multirow{2}{*}{ Mean } & \multirow{2}{*}{ StDv } & \multirow{2}{*}{ CV (\%) } & \multirow{2}{*}{ Mean } & \multirow{2}{*}{$\mathrm{StDv}$} & \multirow{2}{*}{$\mathrm{CV}(\%)$} & \multicolumn{3}{|c|}{ Significance } \\
\hline & & & & & & & & & & $\bar{G}$ & $\mathrm{~L}$ & $\mathrm{G} \times \mathrm{L}$ \\
\hline $\mathrm{CLL}^{\mathrm{H}}$ & $23.66^{* * *}$ & 0.10 & 0.3 & - & - & - & - & - & - & - & - & - \\
\hline $\mathrm{CLW}^{\mathrm{H}}$ & $6.67 * * *$ & 0.66 & 0.1 & - & - & - & - & - & - & - & - & - \\
\hline $\mathrm{DG}^{\mathrm{H}}$ & $11.92 * * *$ & 1.53 & 1.0 & - & - & - & - & - & - & - & - & - \\
\hline DFl & $53.58^{\mathrm{NS}}$ & 4.86 & 8.5 & $52.21 * *$ & 6.05 & 10.2 & 52.99 & 5.55 & 9.5 & $* *$ & $* *$ & $*$ \\
\hline DFr & $62.96^{\mathrm{NS}}$ & 6.5 & 9.6 & $64.93 * * *$ & 6.23 & 7.9 & 64.2 & 6.47 & 8.9 & $* * *$ & $* *$ & NS \\
\hline FL & $10.04 * * *$ & 1.73 & 14.0 & $9.90^{\mathrm{NS}}$ & 1.43 & 13.4 & 9.92 & 1.58 & 14.1 & $* * *$ & NS & NS \\
\hline FW & $2.24 * * *$ & 0.78 & 16.0 & $2.35 * * *$ & 0.79 & 27.7 & 2.31 & 0.78 & 23.2 & $* * *$ & NS & NS \\
\hline FWTh & $2.23 * * *$ & 0.46 & 13.7 & $1.75 * * *$ & 0.44 & 20.6 & 1.98 & 0.51 & 18.4 & $* * *$ & $* * *$ & NS \\
\hline FWt & $16.06^{* * *}$ & 10.4 & 39.4 & $17.13 * * *$ & 9.38 & 37.4 & 16.57 & 9.96 & 39.9 & $* * *$ & NS & $*$ \\
\hline LML & $9.85^{* * *}$ & 2.05 & 17.0 & $9.23 * * *$ & 1.99 & 18.0 & 9.61 & 2.04 & 17.3 & $* * *$ & $* * *$ & NS \\
\hline LMW & $4.68^{* * *}$ & 1.05 & 18.6 & $4.18^{* * *}$ & 0.69 & 12.7 & 4.46 & 0.93 & 15.7 & $* * *$ & $* * *$ & NS \\
\hline $\mathrm{NFr} / \mathrm{P}$ & $60.22 * * *$ & 31.24 & 42.3 & $40.22 * * *$ & 18.82 & 31.3 & 50.3 & 27.53 & 43.5 & $* * *$ & $* * *$ & NS \\
\hline PHt & $45.82^{\mathrm{NS}}$ & 7.61 & 15.8 & $48.29^{* *}$ & 8.04 & 14.2 & 47.3 & 7.90 & 15.1 & $* * *$ & $* *$ & NS \\
\hline STh & $14.37^{*}$ & 2.96 & 19.4 & $13.6^{*}$ & 2.51 & 15.5 & 14.08 & 2.73 & 17.1 & $* * *$ & $* * *$ & NS \\
\hline TSS & $5.34^{\mathrm{NS}}$ & 0.91 & 16.0 & $7.59 * *$ & 1.32 & 15.3 & 6.42 & 1.63 & 16.8 & NS & $* * *$ & $* *$ \\
\hline $\mathrm{Y} / \mathrm{Pl}$ & $633.7 * * *$ & 353.1 & 37.3 & $298.4^{\mathrm{NS}}$ & 134.7 & 35 & 475 & 340.4 & 41.7 & $* * *$ & $* * *$ & $* * *$ \\
\hline
\end{tabular}

Note. $\mathrm{CLL}=$ Cotyledon leaf length; $\mathrm{CLW}=$ Cotyledon leaf width; DFl = Days to flowering; DFr $=$ Days to fruiting; $\mathrm{DG}=$ Days to germination; FL = Fruit length; FW = Fruit width; FWTh $=$ Fruit wall thickness; FWt $=$ Fruit weight; $\mathrm{LML}=$ Leaf mature length; LMW $=$ Leaf mature width; NFr/P $=$ Number of fruits per plant $\mathrm{PHt}=$

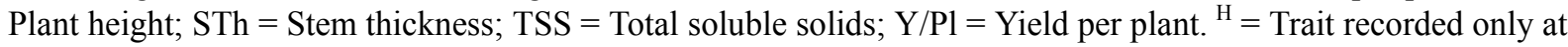
Hamelmalo.

\subsection{Principal Component Analysis}

\subsubsection{Quantitative Traits}

Based on Principal components analysis of the quantitative traits, the first 5 components were found to explain $87 \%$ of the total variation among the genotypes at Hamelmalo and $83 \%$ in Asmara, while analysis of the combined data of the two sites showed $88 \%$. However, due to lower roots in both Asmara and combined of the two sites only the first four components which explained $76 \%$ in Asmara and $82 \%$ in combined data of the two sites were considered (Table 5). The first three components were able to explain $71 \%$ of the variation at Hamelmalo, $65 \%$ in Asmara and 74\% combined of the two sites. PC1was the most important component, which was able to explain $44 \%, 35 \%$ and $46 \%$ of the variation at Hamelmalo, Asmera and combined of the two sites respectively. Both PC 2 and PC 3 were able to explain 17\% and 10\% at Hamelmalo, 18\% and 12\% in Asmara and $16 \%$ and 12\% combined of the two sites respectively (Table 5). The correlation between the components and morphological traits showed slight differences in the two sites and when the combined data of the two sites was considered (Table 6). Data of Hamelmalo and Asmara as well as combined of the two sites showed that PC1 was mainly accounted for by fruit width (FW), fruit wall thickness (FWTh), fruit weight (FrWt) and number of fruits per plant $(\mathrm{NFr} / \mathrm{P})$. PC2 at Hamelmalo was accounted for mainly by days to flowering and days to fruiting. This corresponded to PC3 in Asmara and the combined data of the two sites. Similarly PC3 at Hamelmalo was 
accounted for by mainly plant height (PHt) and yield per plant (Y/P) as well as fruit length (FL) and number of fruits per plant. In both Hamelmalo and Asmara PC4 was accounted for by mainly leaf mature length (LML), leaf mature width (LMW) and fruit length (FL) in addition to stem thickness (STh) only for Hamelmalo. The last three were accounted for by PC4 of the combined data. Finally PC5 in both Hamelmalo and Asmara and PC4 for the combined data were solely accounted for by total soluble solids (TSS) in the fruit (Table 6). It is noteworthy, that both fruit length and number of fruits per plant had no clear structure at Hamelmalo. NFr $/ \mathrm{P}$ scored high in both PC1 and PC3, while fruit length scored high in both PC3 and PC4.

Table 5. Latent roots and percentage variation of quantitative variables recorded at Hamelmalo, Asmara and combined data of the two sites

\begin{tabular}{|c|c|c|c|c|c|c|c|c|c|}
\hline \multirow{2}{*}{$\mathrm{PC}$} & \multicolumn{3}{|c|}{ Hamelmalo } & \multicolumn{3}{|c|}{ Asmara } & \multicolumn{3}{|c|}{ Combined data of the two sites } \\
\hline & Root & $\%$ & Cum & Root & $\%$ & Cum & Root & $\%$ & Cum \\
\hline PC1 & 5.703 & 44 & 44 & 4.573 & 35 & 35 & 6.018 & 46 & 46 \\
\hline PC2 & 2.182 & 17 & 61 & 2.397 & 18 & 53 & 2.108 & 16 & 62 \\
\hline PC3 & 1.359 & 10 & 71 & 1.605 & 12 & 65 & 1.618 & 12 & 74 \\
\hline PC4 & 1.038 & 8 & 79 & 1.395 & 11 & 76 & 0.975 & 8 & 82 \\
\hline PC5 & 0.989 & 8 & 87 & 0.879 & 7 & 83 & 0.76 & 6 & 88 \\
\hline
\end{tabular}

Note. $\mathrm{PC}=$ Principal component; Cum $=$ Cumulative .

Table 6. Eigen vectors of quantitative variables recorded at Hamelmalo, Asmara and the combined data for the two sites

\begin{tabular}{|c|c|c|c|c|c|c|c|c|c|c|c|c|c|c|c|}
\hline \multirow{3}{*}{ Traits } & \multicolumn{15}{|c|}{ Principal Components } \\
\hline & \multicolumn{5}{|c|}{ HAC } & \multicolumn{5}{|c|}{ Asmara } & \multicolumn{5}{|c|}{ Combined data of the two sites } \\
\hline & 1 & 2 & 3 & 4 & 5 & 1 & 2 & 3 & 4 & 5 & 1 & 2 & 3 & 4 & 5 \\
\hline DFl & 0.00 & -0.69 & -0.05 & -0.03 & 0.01 & 0.06 & -0.02 & -0.69 & 0.02 & 0.15 & 0.03 & 0.00 & -0.69 & -0.05 & 0.03 \\
\hline $\mathrm{DFr}$ & 0.05 & -0.70 & -0.01 & -0.04 & 0.00 & -0.04 & 0.00 & -0.65 & 0.01 & -0.12 & 0.01 & 0.01 & -0.67 & 0.06 & 0.03 \\
\hline FL & -0.27 & -0.15 & 0.47 & 0.59 & -0.11 & -0.35 & -0.24 & -0.15 & -0.65 & 0.10 & -0.07 & -0.67 & -0.17 & -0.10 & -0.24 \\
\hline FW & -0.43 & 0.06 & -0.03 & -0.19 & 0.05 & -0.44 & 0.04 & -0.03 & 0.04 & -0.09 & -0.46 & -0.03 & 0.04 & 0.05 & 0.07 \\
\hline FWTh & -0.45 & -0.02 & 0.03 & -0.01 & -0.05 & -0.48 & 0.06 & 0.04 & 0.10 & 0.13 & -0.49 & -0.01 & 0.02 & -0.08 & 0.02 \\
\hline FWt & -0.45 & 0.03 & 0.11 & -0.01 & 0.01 & -0.53 & -0.01 & 0.03 & -0.04 & -0.05 & -0.48 & -0.20 & 0.02 & 0.06 & -0.05 \\
\hline LML & -0.14 & -0.07 & 0.10 & -0.43 & -0.05 & -0.10 & -0.14 & -0.05 & 0.53 & 0.14 & -0.10 & 0.06 & -0.05 & 0.02 & 0.50 \\
\hline LMW & -0.14 & -0.02 & 0.03 & -0.48 & -0.01 & -0.16 & -0.12 & -0.04 & 0.47 & -0.05 & -0.12 & 0.14 & 0.00 & 0.06 & 0.51 \\
\hline $\mathrm{NFr} / \mathrm{P}$ & 0.49 & 0.02 & 0.42 & -0.01 & -0.03 & 0.28 & -0.38 & 0.11 & -0.22 & 0.06 & 0.44 & -0.33 & 0.11 & 0.08 & -0.02 \\
\hline PHt & 0.06 & 0.06 & 0.53 & -0.11 & 0.02 & 0.11 & -0.55 & 0.00 & 0.09 & -0.09 & 0.14 & -0.39 & 0.12 & -0.07 & 0.35 \\
\hline STh & 0.12 & -0.05 & 0.35 & -0.43 & -0.01 & 0.01 & -0.51 & -0.15 & 0.11 & -0.07 & 0.16 & -0.20 & -0.05 & -0.08 & 0.54 \\
\hline TSS & 0.01 & 0.02 & -0.05 & -0.05 & -0.99 & -0.08 & -0.09 & 0.03 & -0.02 & -0.91 & 0.03 & -0.02 & -0.02 & 0.96 & 0.00 \\
\hline $\mathrm{Y} / \mathrm{Pl}$ & -0.19 & 0.02 & 0.42 & -0.03 & 0.03 & -0.22 & -0.43 & 0.21 & 0.03 & 0.25 & -0.21 & -0.43 & 0.06 & 0.14 & 0.07 \\
\hline
\end{tabular}

Note. DFl $=$ Days to flowering; $\mathrm{DFr}=$ Days to fruiting; $\mathrm{FL}=$ Fruit length; $\mathrm{FW}=$ Fruit width; $\mathrm{FWTh}=$ Fruit wall thickness; FWt $=$ Fruit weight; LML = Leaf mature length; LMW = Leaf mature width; $\mathrm{NFr} / \mathrm{P}=$ Number of fruits per plant; $\mathrm{PHt}=$ Plant height; $\mathrm{STh}=$ Stem thickness; TSS $=$ Total soluble solids; $\mathrm{Y} / \mathrm{Pl}=$ Yield per plant.

The Principal coordinate bi-plot result of the first two coordinates using data of the 13 quantitative traits (16 at Hamelmalo) showed that in both sites and with combined data from the two sites the collections were distributed into all the four quadrants (Figures 1 and 2). The spread pattern in the two research sites and combined data of the two sites was similar. All the breeding lines of HAC and NARI (except Group 1 A from NARI) and farmer 
varieties collected from sub-region Afabet located together on the positive side of PC1 axis, while all farmer varieties (with few exceptions in each site) collected from the remaining sub-regions were distributed in the negative area of the same PC. On the other hand the 16 quantitative variables spread into three quadrants. In these three quadrants, NFr/P solitarily located in quadrant 3, while Y/Pl, STh, PHt, FL, CLL, CLW, LML, LMW and TSS in one quadrant and DG, DFl, DFr, FW, FWt and FWTh in another quadrant. Most of the traits except CLL, CLW, TSS and DG tend to spread away from the centre (Figures 1 and 2). However, the width of angle between traits within each quadrant or beyond varied indicating variable correlations among the traits under study. For example the angles separated phenological traits (DFl, DFr and DG) from each other were narrow. Similarly, angels separating fruit characteristics (FW, FWt and FWTh), leaf characteristics (LML and LMW) and $\mathrm{Y} / \mathrm{P}$ with FL and plant growth (PHt and STh) traits also were narrow (Figures 1 and 2).

The position of some individual varieties within the plot area showed slight differences depending on the data collected from the two sites and the pooled data.

Although no grouping differences of the varieties between the bi-plots resulted from the data sets of the two experimental sites, the location of the varieties and variables on the positive and negative sides of the PC 2 axis on the bi-plot of Asmara was reversed to the bi-plot of Hamelmalo (Figure 1). At Hamelmalo, DFl and DFr located in the first quadrant, $\mathrm{PHt}, \mathrm{Y} / \mathrm{Pl}$ and $\mathrm{STh}$ were in quadrant two, while $\mathrm{NFr} / \mathrm{P}$ was in quadrant three. In Asmara and using pooled data, all these traits were in the opposite quadrants (Figures 1 and 2).
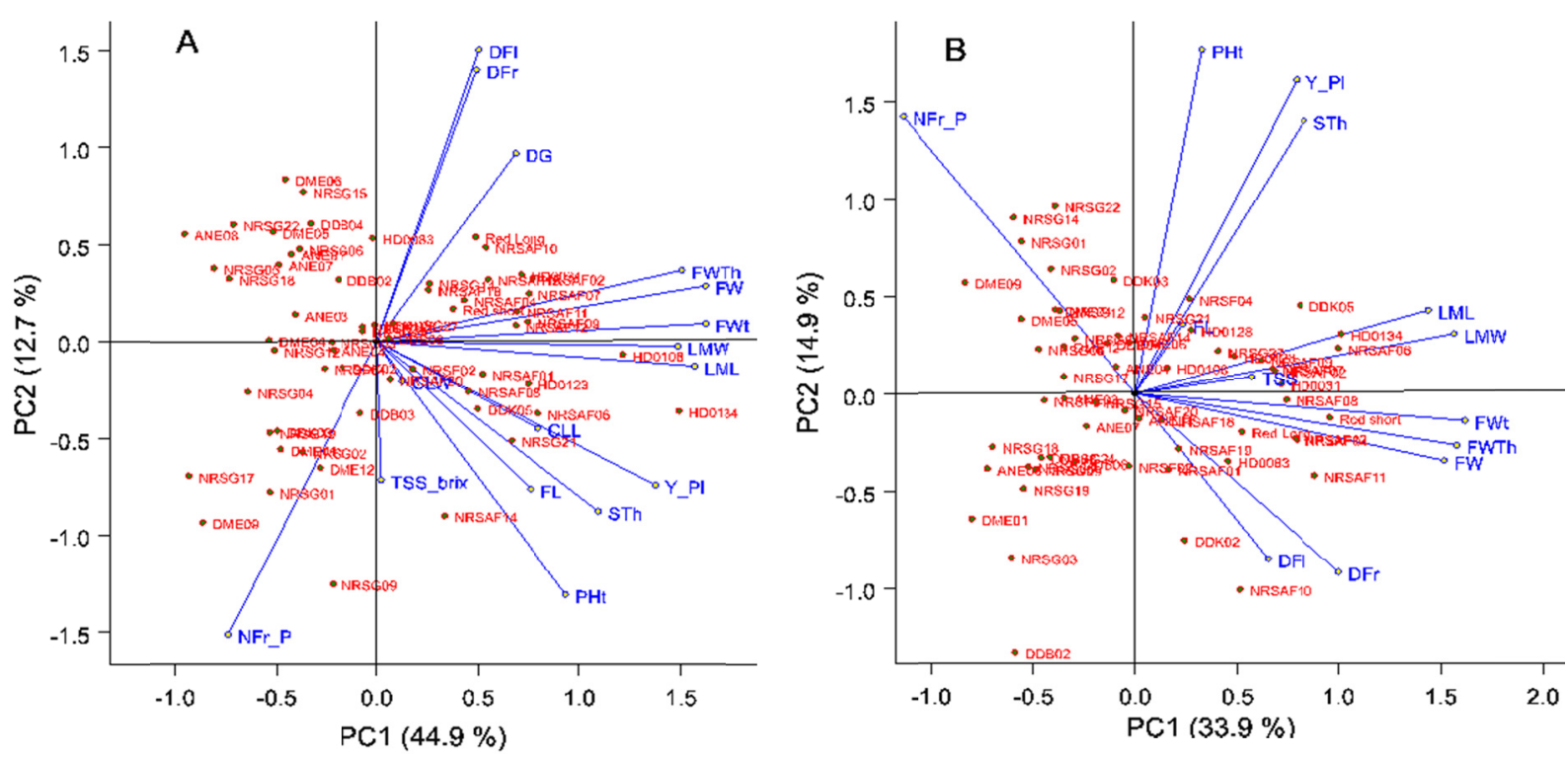

Figure 1. Principal coordinate biplot of the first two PCs using quantitative data from Hamelmalo (A) and Asmara (B) for the 60 collections 


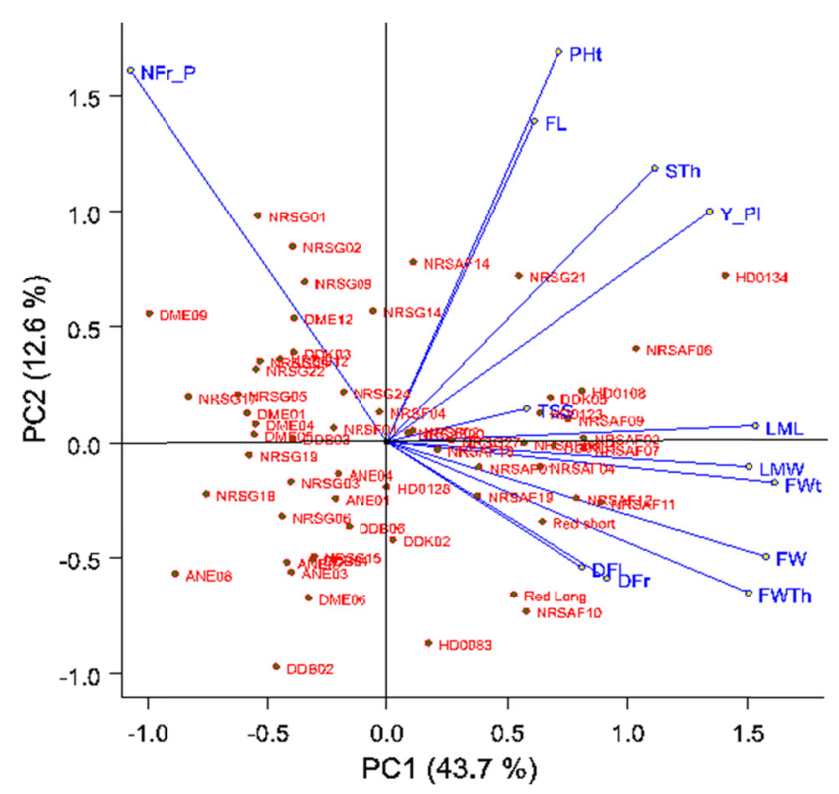

Figure 2. Principal coordinates biplot of the first two PCs using pooled quantitative data of the two sites for the 60 collections

\subsubsection{Qualitative Traits}

The principal component analysis of qualitative traits showed that 13 out of the 23 traits had low or no contributions to the variation among the varieties. Thus the analysis was conducted on the remaining 10 traits that scored loading of 0.4 and above. In this analysis the first four components for the genotypes tested at Hamelmalo and five components for those tested in Asmara and the combined data were able to explain 69\%, $70 \%$ and $75 \%$ of the variation respectively. At Hamelmalo the first three components were able to explain $59 \%$ of the variation of which $29 \%$ was explained by the first component. In Asmara the first three components explained $49 \%$ of which $22 \%$ was explained by the first component. While the combined data showed $55 \%$ of the variation explained by the first three components of which $28 \%$ was by the first component alone (Table 7 ).

Table 7. Latent roots and percentage variation of quantitative variables at Hamelmalo, Asmara sites and using combined data of the two sites

\begin{tabular}{|c|c|c|c|c|c|c|c|c|c|}
\hline \multirow{2}{*}{$\mathrm{PC}$} & \multicolumn{3}{|c|}{ Hamelmalo } & \multicolumn{3}{|c|}{ Asmara } & \multicolumn{3}{|c|}{ Combined of the two sites } \\
\hline & Root & $\%$ & Cum $\%$ & Root & $\%$ & Cum\% & Root & $\%$ & Cum\% \\
\hline $\mathrm{PC} 1$ & 2.867 & 29 & 29 & 2.235 & 22 & 22 & 2.807 & 28 & 28 \\
\hline PC2 & 1.842 & 18 & 47 & 1.449 & 14 & 36 & 1.525 & 15 & 43 \\
\hline PC3 & 1.25 & 12 & 59 & 1.278 & 13 & 49 & 1.15 & 12 & 55 \\
\hline PC4 & 0.973 & 10 & 69 & 1.115 & 11 & 60 & 1.037 & 10 & 65 \\
\hline PC5 & & & & 1.017 & 10 & 70 & 0.952 & 10 & 75 \\
\hline
\end{tabular}

Note. $\mathrm{PC}=$ Principal component $;$ Cum $=$ Cumulative.

The correlation between the traits and components in Table 8 showed that at Hamelmalo and the combined data for PC1 was mainly related to fruit shape components (CAC, FShPA and FShBE) with lower relation to flower position (FP), while in Asmara it was accounted for mainly by CAC and FP. PC2 in the three cases was related to the green color in both fruit and leaf (FCIS and LC). At Hamelmalo PC3 was related to fruit color at mature stage (FCMS) and leaf shape (LSh), in Asmara it was related only to LSh, while with the combined data each of LSh and FCMS were related solely to PC4 and PC5 respectively. PC4 the last component at HAC was related to fruit cross sectional corrugation (FCSC) and plant growth habit (PGH), the two traits were related to $\mathrm{PC} 3$ in the 
combined data of the two sites. While in Asmara PC4 was related to FCMS, FShPA and PGH and PC5 was related to FCSC and FShBE.

Table 8. Eigen vectors of qualitative variable at Hamelmalo, Asmara and combined data of the two sites

\begin{tabular}{|c|c|c|c|c|c|c|c|c|c|c|c|c|c|c|}
\hline \multirow{3}{*}{ Variant } & \multicolumn{14}{|c|}{ Principal Components of the qualitative traits } \\
\hline & \multicolumn{4}{|c|}{ Hamelmalo } & \multicolumn{5}{|c|}{ Asmara } & \multicolumn{5}{|c|}{ Combined } \\
\hline & 1 & 2 & 3 & 4 & 1 & 2 & 3 & 4 & 5 & 1 & 2 & 3 & 4 & 5 \\
\hline CAC & 0.45 & 0.09 & 0.01 & -0.14 & -0.54 & 0.11 & -0.06 & -0.11 & 0.04 & 0.44 & -0.15 & 0.03 & -0.17 & -0.26 \\
\hline FCIS & 0.11 & -0.60 & -0.05 & 0.09 & 0.04 & -0.54 & -0.31 & 0.09 & 0.28 & 0.16 & 0.62 & -0.08 & -0.17 & -0.06 \\
\hline FCMS & -0.02 & -0.33 & -0.59 & 0.20 & 0.47 & 0.13 & 0.31 & -0.58 & 0.05 & 0.10 & -0.08 & -0.03 & -0.01 & 0.91 \\
\hline FCSC & 0.25 & 0.04 & -0.01 & -0.73 & -0.19 & 0.02 & 0.13 & 0.01 & 0.56 & 0.20 & -0.19 & 0.42 & 0.29 & -0.10 \\
\hline FP & -0.36 & -0.14 & -0.27 & -0.14 & 0.61 & 0.05 & -0.19 & 0.06 & -0.01 & -0.36 & 0.04 & 0.22 & -0.17 & 0.23 \\
\hline FShBE & 0.50 & -0.13 & -0.06 & 0.03 & 0.14 & -0.02 & -0.06 & -0.04 & 0.74 & 0.53 & 0.15 & 0.02 & 0.09 & 0.19 \\
\hline FShPA & 0.51 & -0.11 & -0.03 & 0.04 & -0.17 & 0.10 & -0.16 & -0.57 & 0.12 & 0.56 & 0.03 & 0.06 & -0.05 & 0.07 \\
\hline LC & -0.02 & -0.60 & 0.06 & -0.19 & 0.05 & -0.76 & 0.20 & -0.07 & -0.12 & -0.09 & 0.72 & 0.08 & 0.16 & 0.02 \\
\hline LSh & -0.08 & -0.32 & 0.76 & 0.13 & -0.08 & -0.05 & 0.83 & 0.12 & 0.09 & -0.03 & 0.02 & -0.02 & 0.88 & 0.01 \\
\hline PGH & 0.28 & 0.13 & -0.01 & 0.57 & 0.17 & 0.28 & 0.06 & 0.54 & 0.15 & 0.04 & -0.08 & -0.87 & 0.10 & -0.02 \\
\hline
\end{tabular}

Note. CAC $=$ Calyx annular constriction; FCIS $=$ Fruit color at intermediate stage; FCMS $=$ Fruit color at mature stage; FCSC $=$ Fruit cross sectional corrugation; FP $=$ Flower position; FShBE $=$ Fruit shape at blossom end; $\mathrm{FShPA}=$ Fruit shape at pedicel attachment; $\mathrm{LC}=$ Leaf color; $\mathrm{LSh}=$ Leaf shape; $\mathrm{PGH}=$ Plant growth habit.

The results of the principal coordinate bi-plot of the first two coordinates (Figures 3 and 4) showed the general pattern of the varieties distribution in the four quadrants was similar to the bi-plots of the quantitative traits (Figures 1 and 2) in showing variability among the varieties in the two sites. However, slight difference in the grouping and distribution of the variables in the four quadrants was observed. Bi-plot of Hamelmalo showed that the 10 variables were distributed in three quadrants grouping CAC, FCSC and PGH in the first quadrant, LSh, FShPA and FShBE in the upper part of the second quadrant and LC and FCIS in the lower part of the second quadrant and FCMS and FP in the third quadrant (Figure 3A). In each of the four groups the angle among the variables was arrow indicating to association among the traits.

The bi-plot of Asmara showed that the variables distributed in the four quadrants and in wider angles from each other compared to Hamelmalo. It also showed that each PGH and LSh formed a new group and occupied their own quadrant, while the rest remained in their respective grouping (Figure 3B). The bi-plot of the pooled data showed similar trends of the varieties distribution, while for the variables the grouping remained the same, but angling was more wider (Figure 4). However, both PGH and LSh changed again their positions. 

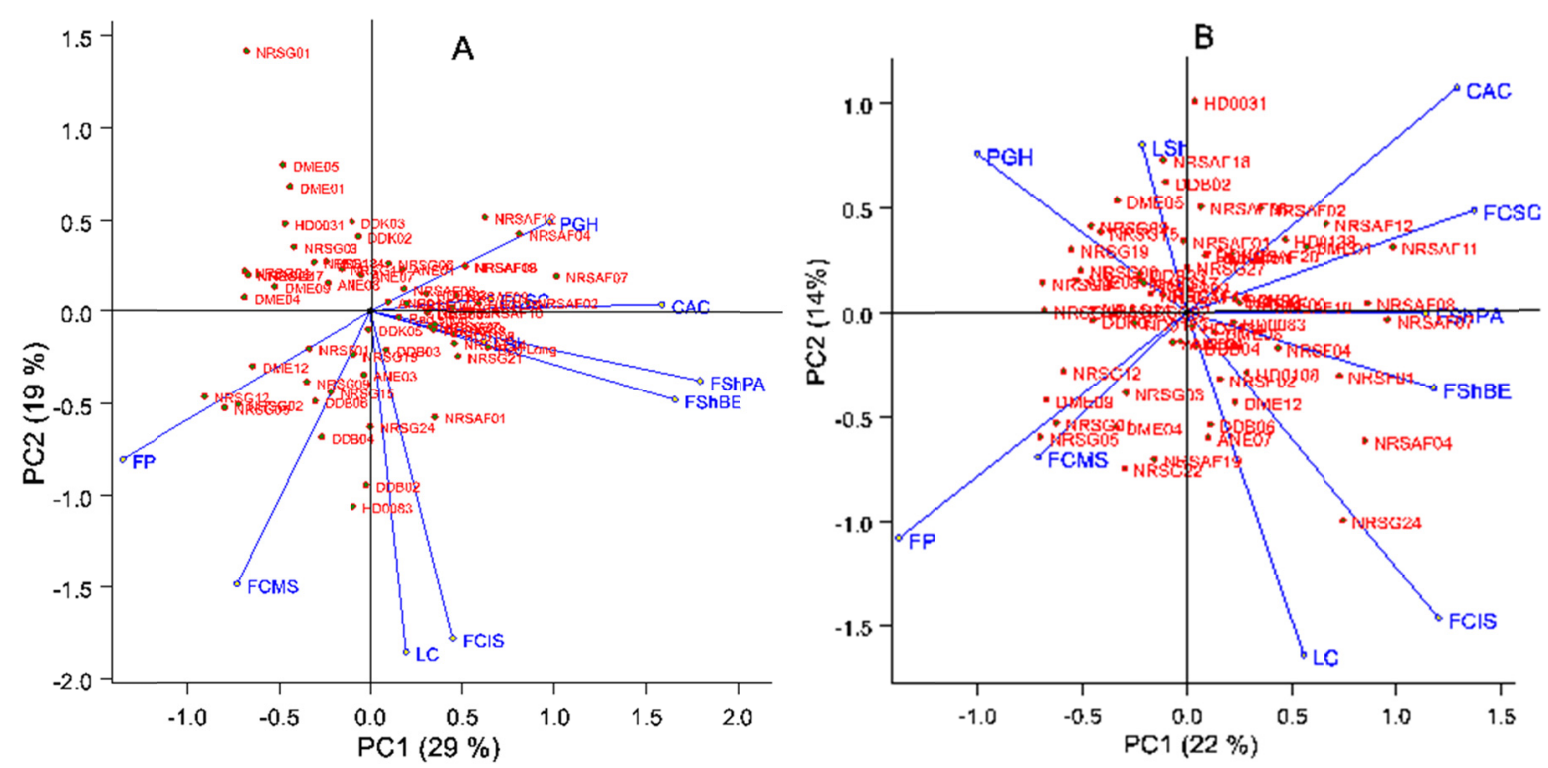

Figure 3. Principal coordinate biplot of the first two PCs using qualitative data from Hamelmalo (A) and Asmara (B) for the 60 c0llections

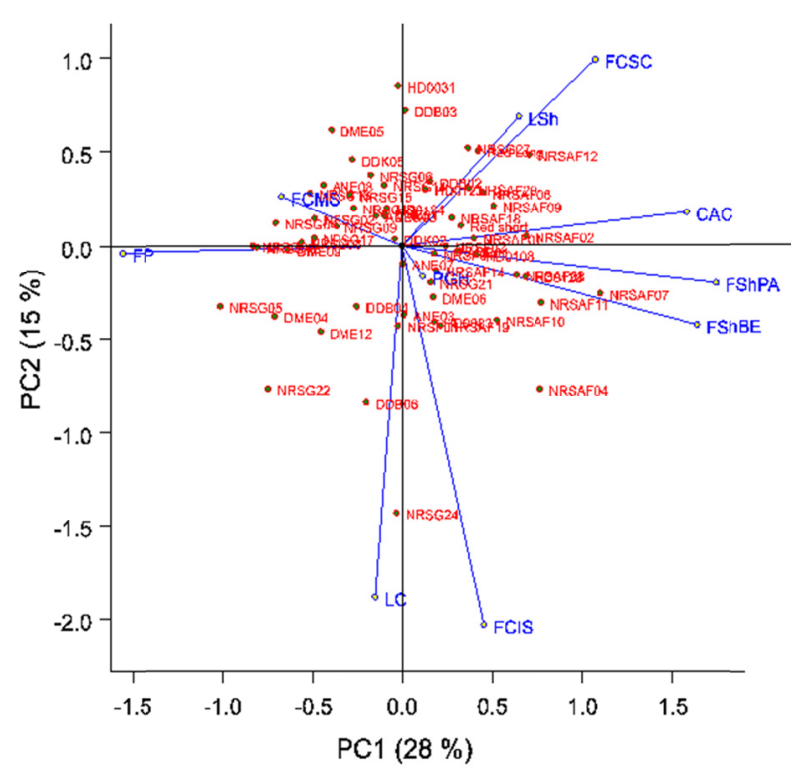

Figure 4. Principal coordinate biplot of the first two PCs using pooled qualitative data of the two sites for the 60 collections

\section{Discussion}

The first step of any meaningful breeding program is to identify crop plants that exhibit exploitable variation for the trait(s) of interest (Aremu, 2012). The distribution of characters of the different quantitative and qualitative traits and the performance of the collections (Tables 2 and 3) showed the existence of variable characters distributed among the collections indicating considerable diversity of collections with respect to phenology, plant and fruit characteristics. The ranges in performance of the collections (Tables 2 and 3), and variations of the quantitative data (Figures 1 and 2), showed the existence of collections with high values of various traits that could be exploited in future breeding programs. A group composed of four collections (HD0134, NRSG 21 HD0031 and NRSAF06) showed high potential for yield (data not shown) that ranged from $1139 \mathrm{~g} / \mathrm{plant}$ (HD0134) to $815 \mathrm{~g} / \mathrm{plant}$ (NRSAF06). This group also showed higher values for yield related traits such as fruit length, fruit width, fruit wall thickness and fruit weight as well as plant height and stem thickness in addition to medium number of fruits per plant. This group was scattered in the quadrants where yield and yield related traits 
were located. A second group composed of NRSG09, NRSG01, DME09 and DME12 which showed high values of number of fruits per plant (79 to 89) and was early in phonological characteristic; days to germination, flowering and fruit set in addition to relatively higher TSS compared to the other groups. This group was scattered in the quadrants where NFr/P was located. This group could be exploited in adding earliness and increasing number of fruits to elite genotypes. A third group composed of four collections (NRSAF 12, NRSAF 14, DDK05 and HD0108) which were medium in almost all traits and recorded yield per plant values ranging from 755 (NRSAF 14) to 572 (DDK05). This group was scattered in either the first or second quadrants at medium distance from most traits. This group could be useful in selecting superior individuals for further improvement.

In some traits, there was limited variation based on the skewed distribution of the collections. In others the collections were evenly distributed across the different characters of the trait (Table 2). The even distribution reflects the variability within the Eritrean pepper germplasm. In addition to that, many traits showed within collection variation resulted in mixed of characters. Due to the high outcross that ranges in pepper $0.5-91 \%$ (do Rego et al., 2012; Bosland, 1996) and possibility of interspecies cross in pepper, it is logical to observe this variation, specially most of the pepper growers in Eritrea are small scale farmers who cultivate small lands adjacent to each other and save their seed from selected plants in the field or the crop after harvest.

The lowest $\mathrm{CV} \%$ was recorded on phenological attributes such as DFl and DFr. Similar results were reported by Ballina-Gómez et al. (2013). The principal coordinates biplots also showed similar distribution of collection. NBF recorded the highest CV\% (180) indicating high within character variation. CAC, FCMS, FSh, and FShBA are traits that recorded high $\mathrm{CV} \%$ of qualitative characteristics. For CAC even a much higher level of coefficient of variation (576.9\%) was reported by Ballina-Gómez et al. (2013) which indicated the importance of these traits for discriminating genotypes.

The high variation recorded on yield components and fruit characteristics (Tables 2 and 3) reflected the intensity of selection for yield and fruit quality parameters. This is similar to the situation of New Mexico pepper landraces described by Votava et al. (2005) which were heterogeneous and survived a long period of selection by farmers for various traits and adapted to local conditions as a result of natural selection.

The principal coordinates biplots (Figures 1-4) displayed more than $48 \%$ of the variation existed among the genotypes based on the quantitative data of the two sites. This could be explained by the first two PCs. It supports the results of the analysis of variance.

For quantitative traits the results showed that the genotypes were significantly different for 12 out of 16 variables in the two locations. Moreover, the combined data analysis of the two sites showed that the difference among genotypes was significant for all variables except for TSS, however, location had a significant effect on TSS which was in agreement with Geleta and Labuschange (2006) who found influence of environment on TSS. The highest coefficient of variation for quantitative traits in the two sites was observed on yield components such as NFrP, FWt and Y/P. This was similar to the results reported by Nsabiyera et al. (2013) in pepper and Naujeer (2009) in eggplant.

The variation explained by the five principal components of the quantitative traits (Table 6) was somewhat similar to the results obtained in previous studies in pepper and other crops as reported by Occhiuto et al. (2014), Nsabiyera et al. (2013), Del et al. (2007), Beyene et al. (2005) and Naugeer (2009). The variation was slightly lower when compared to those reported by Aruah et al. (2010). However, the variation was much higher than other studies conducted previously on pepper and other crops (Bozokalfa et al., 2009; Furat \& Uzun, 2010).

The variation explained by the first five components (four at Hamelmalo) from the ten qualitative traits (Table 8) was much lower at Hamelmalo and Asmara and slightly lower in the combined data than the results of Aruah et al. (2010) who evaluated variation in cucumber (74.94\% from the first three components), and Del et al. (2007) who reported $82 \%$ in pepper. On the other hand similar results were reported for the first three components (57\%) and a lower percentage (21\%) for the first component.

Occhiuto et al. (2014) found fruit characteristics as the most efficient traits in the differentiation of the accessions. In the current study both quantitative and qualitative fruit characteristics were the most important contributors in explaining the variation among the genotypes. These are fruit width, fruit wall thickness, fruit weight and number of fruits per plant of quantitative traits and fruit shape at blossom end, fruit shape at pedicel attachment and fruit color at intermediate stage. However, for qualitative traits this was true for Hamelmalo and combined data, while in Asmara fruit shape at both pedicel attachment and blossom end were less important compared to fruit color at mature stage. 
Other characteristics that were important contributors for differentiating among genotypes are phonological attributes (DFl and DFr) and vegetative growth (PHt and STh) of the quantitative and CAC, LC and FP of the qualitative variables. These results were similar to the results reported by Nsabiyera et al. (2013), Cankaya et al. (2010); and Del et al. (2007) for the quantitative traits. While for qualitative traits they were similar to the findings of Del et al. (2007) regarding flower position, leaf and fruit color.

Understanding the correlation among plant traits is important for breeders in selecting superior genotypes for yield and other characteristics. Cankaya et al. (2010) found determining the relationship between characters affecting optimum output is very important for increasing yield components in pepper genotypes. In the current study yield per plant had variable degrees of relationship with almost all yield components (FL, FW, FWt, FWTh and $\mathrm{NFr} / \mathrm{P}$ ) and vegetative growth traits (PHt, STh, LML and LMW) (Figures 1 and 2). However, the correlation was strong with FL, PHt and STh, weak with $\mathrm{NFr} / \mathrm{P}$ and medium with the rest. In studying old pepper cultivars from Serbia, Ilic et al. (2013) reported similar results regarding FWt, FWTh and NFr/P but contrary on PHt. In contrary to our results, Abu et al. (2013) found strong correlation between plant height and fruit length, but reported the correlation of both traits to yield to be non significant. Furthermore, they found a negative association between yield/plant and both fruit weight and pericarp thickness and strong correlation between number of fruits/plant and yield/plant. In eggplant Toppino et al. (2013), reported strong correlation between yield and yield related traits (number of fruits, fruit weight, fruit length and fruit width). The traits also were correlated to each other.

\section{Conclusions}

The Eritrean pepper germplasm was found to be diverse with respect to quantitative and qualitative morphological traits. The diversity which is available among the Eritrean pepper genotypes is enough to support a pepper breeding and improvement program at least for yield and fruit quality. Plant height, stem thickness, fruit length and other traits can be potentially useful for selecting high yielding genotypes in breeding process.

\section{References}

Abu, N. E., Uguru, M. I., \& Obi, I. U. (2013). Genotypic stability and correlation among quantitative characters in genotypes of aromatic pepper grown over years. African Journal of Biotechnology, 12(20), 2792-2801.

Adetula, A. O., \& Olakojo, S. (2006). Genetic characterization and evaluation of some pepper accesions Capsicum frutescens (L.): The Nigerian "Shombo" collections. American-Eurasian Journal Agriculture and Environment Science, 1(3), 273-281.

Aremu, C. O. (2012). Exploring statistical tools in measuring genetic diversity for crop improvement. INTECH Open Access Publisher. Retrieved from http://www.intechopen.com

Aruah, C. B., Uguru, M. I., \& Oyiga, B. C. (2010). Variations among some Nigerian Cucurbita landraces. African Journal of Plant Science, 4(10), 374-386.

Balkaya, A., \& Karaagc, O. (2009). Evaluation and Selection of Suitable Red Pepper (Capsicum annuum var. conoides Mill.) Types in Turkey. Asian Journal of Plant Science, 8(7), 483-488. http://dx.doi.org/10.3923/ajps.2009.483.488

Ballina-Gómez, H., Latournerie-Moreno, L., Ruíz-Sánchez, E., Pérez-Gutiérrez, A., \& Rosado-Lugo, G. (2013). Morphological characterization of Capsicum annuum L. accessions from southern Mexico and their response to the Bemisia tabaci-Begomovirus complex. Chilean Journal of Agricultural Research, 73(4), 329-338. http://dx.doi.org/10.4067/S0718-58392013000400001

Beyene, Y., Botha, A., \& Myburg, A. A. (2005). A comparative study of molecular and morphological methods of describing genetic relationships in traditional Ethiopian highland maize. African Journal of Biotechnology, 4(7), 586-595. Retrieved from http://www.academicjournals.org/AJB

Bosland, P. W. (1996). Capsicums: Innovative uses of an ancient crop. In J. Janick (Ed.), Progress in new crops (pp. 479-487). ASHS Press, Arlington, VA.

Bozokalfa, M. K., Eşiyok, D., \& Turhan, K. (2009). Patterns of phenotypic variation in a germplasm collection of pepper (Capsicum annuum L.) from Turkey. Spanish Journal of Agricultural Research, 7(1), 83-95. http://dx.doi.org/10.5424/sjar/2009071-401

Cankaya, S., Balkaya, A., \& Karaagac, O. (2010). Canonical correlation analysis for the determination of relationships between plant characters and yield components in red pepper [Capsicum annuиm L. var. conoides (Mill.) Irish] genotypes. Spanish Journal of Agricultural Research, 8(1), 67-73. http://dx.doi.org/10.5424/sjar/2010081-1144 
Del, E., Pérez, C. M., Álvarez, O. C., Arrazate, C. H. A., \& Damián, M. A. T. M. (2007). Morphological variation in Guajillo chili pepper plants (Capsicum annuum L.). Crop Science, 8, 327-332.

Do Rêgo, E. R., \& Nascimento, M. F., do Nascimento, N. F. F., dos Santos, R. M. C., Fortunato, F. L. G., \& do Rêgo, M. M. (2012). Testing methods for producing self-pollinated fruits in ornamental peppers. Horticultura Brasileira, 30(4), 669-672. http://dx.doi.org/10.1590/S0102-05362012000400017

Furat, S., \& Uzun, B. (2010). The use of agro-morphological characters for the assessment of genetic diversity in sesame (Sesamum indicum L.). Plant Omics Journal, 3(3), 85-91.

Geleta, L. F., \& Labuschagne, M. T. (2006). Combining ability and heritability for vitamin C and total soluble solids in pepper (Capsicum annuum L.). Journal of the Science of Food and Agriculture, 86(9), 1317-1320. http://dx.doi.org/10.1002/jsfa.2494

Govindaraj, M., Vetriventhan, M., \& Srinivasan, M. (2015). Importance of Genetic Diversity Assessment in Crop Plants and Its Recent Advances: An Overview of Its Analytical Perspectives. Genetics Research International. $\mathrm{http}: / / \mathrm{dx}$.doi.org/10.1155/2015/431487

Ilic, Z. S., Milenkovic, L., Vasic, M., Girek, Z., Zdravkovic, M., \& Zdravkovic, J. (2013). Old cultivars and populations from traditional pepper-growing regions of Serbia as breeding potential. Journal of Agricultural Science, 5(6), 132-140. http://dx.doi.org/10.5539/jas.v5n6p132

IPGRI, AVRDC, \& CATIE. (1995). Descriptors for Capsicum (Capsicum spp.) (p. 114). International Plant Genetic Resources Institute; Asian Vegetable Research and Development Center and Tropical Agricultural Research and Training Centre.

Nsabiyera, V., Ochwo-ssemakula, M. L. M., Sseruwagi, P., Gibson, P., \& Ojiewo, C. (2013). Morphological Characterization of Local and Exotic Hot Pepper (Capsicum annuum L.) Collections in Uganda. Bioremediation, Biodiversity and Bioavailability. Global Science Books.

NARI. (2013). Annual reports of 2003-2012. Horticulture Research Unit, Crop Improvement Division, National Agricultural Research Institute, Halhale, Eritrea.

Occhiuto, P. N., Peralta, I. E., Asprelli, P. D., \& Galmarini, C. R. (2014). Characterization of Capsicum germplasm collected in Northwestern Argentina based on morphological and quality traits. Agriscientia, 31(2), 63-73.

Rao, V. R., \& Hodgkin, T. (2002). Genetic diversity and conservation and utilization of plant genetic resources. Plant Cell, Tissue and Organ Culture, 68(1), 1-19. http://dx.doi.org/10.1023/A:1013359015812

Toppino, L., Barchi, L., Rotino, G. L., Valè, G., Acciarri, N., Ciriaci, T., ... Lanteri, S. (2013). Mapping of QTLs for key breeding traits in eggplant (Solanum melongena L.). In S. Lanteri \& G. L. Rotino (Eds.), Breakthroughs in the Genetics and Breeding of Capsicum and Eggplant: Proceedings of the XV EUCARPIA Meeting on Genetics and Breeding of Capsicum and Eggplant (pp. 177-185). Torino, Italy: Comitato per l'organizzazione degli eventi (COE) DISAFA, Università degli Studi di Torino. Retrieved from http://www.chilepepperinstitute.org/content/files/Proceedings_Torino_2013.pdf

Votava, E. J., Baral, J. B., \& Bosland, P. W. (2005). Genetic Diversity of Chile (Capsicum Annuum var. Annuum L.) Landraces from Northern New Mexico, Colorado, and Mexico. Economic Botany, 59(1), 8-17. http://dx.doi.org/10.1663/0013-0001(2005)059[0008:GDOCCA]2.0.CO;2

\section{Copyrights}

Copyright for this article is retained by the author(s), with first publication rights granted to the journal.

This is an open-access article distributed under the terms and conditions of the Creative Commons Attribution license (http://creativecommons.org/licenses/by/3.0/). 